SOPHIE MACAULAY

\title{
SHOULD THE USE OF AN ALTERNATIVE TRIAL PROCESS PRECLUDE REFERRAL BACK TO THE CRIMINAL JUSTICE SYSTEM? CONSIDERATION OF ONE ASPECT OF THE LAW COMMISSION'S PROPOSAL FOR TRIAL PROCESS REFORM IN CASES OF SEXUAL OFFENDING
}

Submitted for the LLB (Honours) Degree

Faculty of Law

University of Wellington

2013 


\section{Abstract}

In its recent Issues Paper, Alternative Pre-Trial and Trial Processes: Possible Reforms, the New Zealand Law Commission proposed to make available some form of restorative justice process as a complete alternative to the criminal justice system in certain sexual offence cases. It also proposed that where an offender participates in an alternative process in good faith and fulfils all undertakings, the case cannot be referred back to the criminal justice system. This paper considers situations where alternative trial processes should be referred back to the criminal justice system and what should happen to material disclosed during the alternative process if referral occurs.

If restorative processes are to be used as a complete alternative to the criminal justice system, there must a "public safety override" which prioritises public safety over victim autonomy. This override will be applied by restorative justice providers, who will have the ability to refer cases back to the criminal justice system. If referral does occur, the content of the restorative proceedings should be privileged, and that privilege should belong to the offender. The fact of the offender's agreement to participate should also be privileged.

\section{Key words}

sexual offending, restorative justice, alternative trial process, referral back to criminal justice system 


\section{Introduction}

New Zealand has led the world in the implementation of restorative justice processes. The Family Group Conference model for young offenders was introduced in 1989, and more recently restorative justice processes have received statutory recognition in the Sentencing Act 2002 and the Parole Act 2002. These Acts encourage the use of restorative justice processes where appropriate. Yet there has been a general reluctance to use restorative justice processes in cases of sexual offending. ${ }^{1}$ Despite this reluctance, there remains widespread support among those working in both the criminal justice and the sexual violence sectors for a more innovative range of responses to sexual offending in New Zealand. ${ }^{2}$ One of the possible alternative responses is the availability of some form of restorative justice process to deal with some sexual offence cases.

The New Zealand Law Commission has described the traditional criminal justice process as "limited in its ability to deliver justice." Anne-Marie McAlinden is more direct in her critique: "When it comes to sexual offences... the salient point is that the traditional retributive form of state justice does not seem to be working." ${ }^{\text {In }}$ response to the Law Commission's 2008 recommendation of an inquiry into the possible modification of the adversarial criminal justice process, ${ }^{5}$ the Government requested that the Law Commission investigate "the extent to which a new framework and/or new processes should be developed to deal with sex offence cases." "In February 2012, the Commission published Alternative Pre-Trial and Trial Processes: Possible Reforms, ${ }^{7}$ an Issues Paper which contained discussion of "an alternative process outside of the criminal justice system" which would deal with certain kinds of sexual offence cases. The alternative process proposed was a restorative process of some form.

\footnotetext{
${ }^{1}$ This reluctance stems largely from the concern that the power imbalance inherent in most sexual offending will be replicated in a restorative process. See for example, the contributions to James Ptacek (ed) Restorative Justice and Violence Against Women (Oxford University Press, Oxford, 2010) which canvass both sides of this debate.

${ }^{2}$ As evidenced by the strong support of proposed reforms in the Law Commission's Alternative Pre-Trial and Trial Processes: Possible Reforms (NZLCIP30, 2012). See also Kathleen Daly, "Restorative Justice and Sexual Assault: An Archival Study of Court and Conference Cases" (2006) 46 Brit J Criminol 334.

${ }^{3}$ Law Commission Alternative Pre-Trial and Trial Processes: Possible Reforms (NZLCIP30, 2012) at 7.

${ }^{4}$ Anne-Marie McAlinden "The use of shame with sexual offenders" (2005) 45 Brit J Criminol 373 at 373.

${ }^{5}$ Law Commission Disclosure to Court of Defendants' Previous Convictions, Similar Offending, and Bad Character (NZLC R103, 2008).

${ }^{6}$ Law Commission, "Alternatives" above n 3, at 6.

${ }^{7}$ At 6 .

${ }^{8}$ At 50 .
} 
Restorative justice (RJ) is notoriously difficult to define, and the term encompasses a wide range of practices. RJ scholar Howard Zehr has suggested the following definitions which are helpful in this context: ${ }^{9}$

Restorative justice requires, at a minimum, that we address victims' harms and needs, hold offenders accountable to put right those harms, and involve victims, offenders, and communities in this process.

Restorative justice is a process to involve, to the extent possible, those who have a stake in a specific offense and to collectively identify and address harms, needs, and obligations, in order to heal and put things as right as possible.

Despite its diversity in practice, RJ typically incorporates a number of key aspects: ${ }^{10}$

(a) The victim has an opportunity to tell the offender about how the offending has affected them.

(b) The offender has an opportunity to apologise for their actions.

(c) The victim has the ability to gain some form of reparation for the harm they have suffered.

Thus the Law Commission's proposed alternative process would enable a victim of sexual offending to meet with the offender in a restorative conference setting, allowing communication between parties and an opportunity for victim and offender to agree on an appropriate form of redress.

Public submissions were invited on the Commission's Issues Paper, and in December 2012 a summary of those public submissions was published. The proposed alternative process for sexual offence cases received "very strong support". ${ }^{11}$ However, a number of submitters noted that there needed to be more detail about the interaction between the proposed alternative process and the criminal justice system. ${ }^{12}$

The Issues Paper posited that if a sexual offender participates in a restorative process in good faith and fulfils all undertakings, referral of the case back to the criminal

\footnotetext{
${ }^{9}$ Howard Zehr The Little Book of Restorative Justice (Good Books, Intercourse (Penn), 2003) at 37.

${ }^{10}$ Tina S Ikpa "Balancing Restorative Justice Principles and Due Process Rights in Order to Reform the Criminal Justice System” (2007) 24 Washington University Journal of Law and Policy 301 at 303.

11 "It was supported, at least provisionally, by all legal stakeholders, sexual and family violence sector organisations and other organisations that commented on it, and most individuals." See Law Commission Alternative Pre-Trial and Trial Processes: Summary of Submissions to Consultation (2012) at 5.

${ }^{12}$ Law Commission, "Submissions" above n 11, at 108.
} 
justice system will be precluded. ${ }^{13}$ In other words, a successfully undertaken alternative process would be a complete alternative to prosecution of the offender in the criminal system. RJ conferences in New Zealand are currently used at various stages of the criminal justice process, most commonly pre-sentencing after a referral from the District Court. ${ }^{14}$ The alternative process proposal would see the victim and offender choosing to pursue a restorative process instead of criminal prosecution. The victim would subsequently lose access to the traditional criminal justice system, provided that the offender participated in the alternative process in good faith and fulfilled all undertakings made as a result of the process.

A number of complex questions arise with the availability of an RJ process as a complete alternative to the criminal justice system. For example, what should happen if in the process of a restorative conference, an offender reveals that he or she has sexually offended against another person? Or even a number of other people? What if those people are children? Should a victim retain their right to have their case tried in the criminal justice system if an offender refuses to agree to the victim's desired redress? Who should decide what level of redress is appropriate?

This paper will explore some of these difficult questions which arise at the interface between RJ and the criminal justice system. I begin by explaining why RJ may provide an appropriate alternative to the criminal justice system in some sexual offence cases. In Part III I suggest that it is appropriate to preclude a case which proceeds through an alternative trial process from entering the criminal justice system, except in three scenarios identified by the Law Commission. In Part IV I address some of the practical issues which may arise in these three scenarios where referral back to the criminal justice system is deemed appropriate or necessary. Finally, in Part V I argue that clear protocols around the use of any material disclosed during the restorative process are necessary. These protocols should ensure that any information revealed in restorative proceedings is privileged. The offender's agreement to participate in a restorative process should also be privileged. To assist in drawing these conclusions, I will draw on the experiences of two

\footnotetext{
${ }^{13}$ Law Commission, "Alternatives" above n 3, at 51.

${ }^{14}$ Ministry of Justice Principles of Best Practice for Restorative Justice Processes in Criminal Cases (2003) at 7.
} 
existing groups who have used restorative processes in sexual offending cases: the RESTORE programme in Arizona, and Project Restore in Auckland.

For the purposes of this paper, I use the terms "victim" and "offender" to describe the parties to the alleged sexual offending, while acknowledging the use of other terminology by those working in the sector. ${ }^{15}$

\section{Why use restorative justice as an alternative response to sexual offending?}

There are a number of reasons why a restorative process may be a more appropriate response than the criminal justice system in some sexual offending cases. Sexual offending in New Zealand attracts high penalties, with a presumption in favour of imprisonment for cases of sexual violation. ${ }^{16}$ There is often little evidence available except the parties' differing versions of events. Forensic evidence is rendered useless if both parties concede that a sexual encounter took place. This inevitably leads prosecutors to question the likelihood of conviction, and makes a guilty plea from an offender very unlikely. ${ }^{17}$ Conviction rates for sexual offending in New Zealand are low. ${ }^{18}$

In cases where there is no denial of a sexual encounter but an acquittal based on reasonable grounds for believing in consent, there is no opportunity for the victim to have acknowledgement of harm caused. ${ }^{19}$ Many victims of sexual offending are reluctant to go through a full adversarial trial, which can be humiliating, whether or not there is a guilty verdict. Even if there is a guilty verdict, some argue that the litigation experience allows little room for healing. ${ }^{20}$

Moreover, in the majority of sexual offending cases, the offender is known to the victim. ${ }^{21}$ Often, as the Law Commission recognises, the outcome of criminal prosecution is

\footnotetext{
${ }^{15}$ See Shirley Jülich's helpful discussion of sexual offending terminology in "Breaking the Silence: Restorative Justice and Child Sexual Abuse" (PhD Thesis, Massey University, 2001) at 21.

${ }^{16}$ Crimes Act 1961, s 128B(2).

${ }^{17}$ Elisabeth McDonald and Yvette Tinsley “Rejecting 'one size fits all': Recommending a range of responses" in Elisabeth McDonald and Yvette Tinsley (eds) From "Real Rape" to Real Justice (Victoria University Press, Wellington, 2011) 377 at 378.

${ }^{18}$ Sue Triggs and others Responding to Sexual Violence: Attrition in the New Zealand Criminal Justice System (Ministry of Women's Affairs, Wellington, 2009).

${ }^{19}$ McDonald and Tinsley, above n 17, at 414.

${ }^{20}$ Arielle Dyland, Cheryl Regehr and Ramona Alaggia “And Justice for All? Aboriginal Victims of Sexual Violence" (2008) 14 Violence Against Women 678 at 679.

${ }^{21}$ See Pat Mayhew and James Reilly The New Zealand Crime and Safety Survey 2006: Key Findings (Ministry of Justice, Wellington, 2007), which found that over a third of sexual offences were committed by a current partner.
} 
at odds with what the victim desires. Some victims may not want the offender to go to prison, particularly if the offender has an ongoing relationship with the victim. For example, the offender may be the father of the victim's children, or the sole income earner in the victim's household. ${ }^{22}$ These shortcomings of the current system have led some to question whether "the current justice process therefore offers the possibility of closure, of validation for victims and of treatment for offenders. ${ }^{, 23}$

Restorative justice offers a more flexible response to sexual offending, enabling victim participation in both the process and the development of a redress plan. A restorative process could be used in cases which are unlikely to be resolved through the criminal system for a lack of evidence. Victims who, for whatever reason, do not wish to engage with the criminal system could seek treatment for the offender and healing of harm through a restorative process. Pursuing a restorative resolution would avoid the potential humiliation of litigation. For a victim who does not desire the imprisonment of the offender, an RJ process offers reparation while minimising the likelihood of a prison sentence. Finally, Kathleen Daly argues that restorative processes can be less victimising than adversarial trials. ${ }^{24}$

Daly also identifies some of the main concerns about the use of RJ in sexual offence cases. The informality of RJ may put victim safety at risk because of the gendered nature of sexual offending, discussed further below. It may also enable offenders to manipulate the process, shifting blame or diminishing guilt in a way that would not be possible in court. Victims may feel pressured to pursue a restorative process and may not be able to advocate for themselves as strongly as a lawyer could. Sexual offence cases often involve complex interpersonal dynamics, thus undermining the effectiveness of family and friends as support people at conferences. ${ }^{25}$

Despite these concerns Daly and others remain supportive of the use of RJ in sexual offence cases. A formal RJ response to sexual offending that has been pioneered in Arizona through the RESTORE programme may offer guidance for the New Zealand context.

\footnotetext{
${ }^{22}$ Law Commission, "Alternatives" above n 3, at 49.

${ }^{23}$ McDonald and Tinsley, above $\mathrm{n} 17$, at 378 .

${ }^{24}$ Kathleen Daly, "Restorative Justice and Sexual Assault: An Archival Study of Court and Conference Cases" (2006) 46 Brit J Criminol 334 at 352.

${ }^{25}$ At 337.
} 
RESTORE (Responsibility and Equity for Sexual Transgressions Offering a Restorative Experience) was a programme set up in Pima County, Arizona, to provide an alternative resolution for cases of sexual offending. Its mission was "to facilitate a victimcentred, community driven resolution of selected individual sex crimes that creates and carries out a plan for accountability, healing and public safety." 26 RESTORE facilitated restorative conferences between the victim (who was termed the "survivor/victim") and the offender (termed the "responsible person"). The conferences were organised by a convenor, whose role was to ensure that the conference discussion covered all the components deemed necessary: a description of the act, identification of the harm, and the formulation of a redress plan. At the conclusion of the restorative conference, a redress plan was signed by the victim/survivor and the responsible person. ${ }^{27}$

A Community Accountability and Reintegration Board (CARB) was established to represent the community in validating the violation of the victim/survivor and in publically condemning sexual offending. The responsible person's progress was regularly reported to the CARB. ${ }^{28}$ RESTORE described itself as "designed to balance the needs of survivors, responsible persons, and the community including family and friends, as well as the broader community that the Community Accountability and Reintegration Board (CARB) represents." The option RESTORE provided ended when its funding from the United States Center for Disease Control and Prevention ended. ${ }^{29}$

\section{B Closer to home: New Zealand's restorative approach to sexual offending through} Project Restore

Project Restore is a provider group using RJ to address sexual violence in the Auckland region. ${ }^{30}$ The model they use is an extended version of the RJ model implemented by the New Zealand Court-Referred Pilot Programme for Restorative Justice, and they have incorporated the Ministry of Justice Principles of Best Practice for

\footnotetext{
${ }^{26}$ Mary P Koss and others "Expanding a Community's Justice Response to Sex Crimes Through Advocacy, Prosecutorial, and Public Health Collaboration: Introducing the RESTORE Program" (2004) 19 J Interpers Violence 1435 at 1448.

${ }^{27}$ At 1451 .

${ }^{28}$ At 1452.

${ }^{29}$ McDonald and Tinsley, above $\mathrm{n} 17$, at 402.

${ }^{30}$ Shirley Jülich and others Project Restore: An Exploratory Study of Restorative Justice and Sexual Violence (AUT, Auckland, 2010) at 5.
} 
Restorative Justice in Criminal Cases. ${ }^{31}$ Project Restore conducts restorative conferences involving the victim and the offender, an RJ facilitator with an understanding of sexual violence, a community expert for both the victim and the offender, and a clinical psychologist. The restorative conferencing model used was developed in New Zealand, initially in the form of family group conferences in the youth justice system. ${ }^{32}$

As noted earlier, RJ is not widely used in the context of sexual offending. RESTORE, Project Restore and Phaphamani Rape Crisis Counselling Centre in South Africa are the only programmes worldwide using RJ to address sexual offending in the adult jurisdiction. ${ }^{33}$ By implementing a widely available alternative process as a complete alternative to criminal prosecution, New Zealand would again be leading the world in RJ innovation. Therefore, it is important to identify problems which may arise in relation to the practical application of the alternative process. It is necessary to carefully consider how the proposed alternative process will interact with the criminal justice system, and to create protocols for referral back to the criminal justice system. The first issue to be addressed is whether precluding a successful alternative process from referral back to the criminal system is appropriate.

\section{Why preclude a successful alternative process from referral back to the} criminal justice system?

If both victim and offender opt to pursue the proposed alternative trial process and that process is undertaken successfully, criminal prosecution for the same offence would be precluded. ${ }^{34}$ The Law Commission identified a number of important reasons for this. Firstly, the Commission acknowledges that "without such an arrangement, there may be little incentive for the accused person to participate in the process." 35 An offender is more likely to participate fully and seek meaningful resolution through the alternative process if it means that criminal prosecution will not be pursued. Secondly, if a victim and offender choose to engage fully in a restorative process, it is important that the restorative outcomes are a final resolution, and provide closure. ${ }^{36}$ Once agreed restorative outcomes have been

\footnotetext{
${ }^{31}$ Ministry of Justice Principles of Best Practice for Restorative Justice Processes in Criminal Cases (2003).

32 Jülich and others, above $\mathrm{n} 30$, at 5 .

${ }^{33}$ At 9

${ }^{34}$ Law Commission, "Alternatives" above n 3, at 51 .

${ }^{35}$ At 52 .

${ }^{36}$ At 52 .
} 
reached and fulfilled, it is in both parties' interests that there does not remain a possibility of criminal proceedings.

Finally, the Law Commission recognised that if a restorative process requires the offender to fulfil any number of undertakings, which may incorporate a penal element, it would be inappropriate to subsequently expose the offender to the criminal justice system; this would infringe the rights of the accused and raise double jeopardy issues. One submitter to the Issues Paper argued that the proposed alternative process was an administrative rather than a judicial response and therefore the double jeopardy defence should not be available. ${ }^{37}$ However, regardless of whether double jeopardy arises in such circumstances, the Law Commission's concern about punishing offenders twice for the same offence is a valid one. If an offender fulfils all restorative process obligations, they should not subsequently be required to proceed through the criminal justice system.

There are, then, a number of valid reasons why preclusion from entering the criminal justice system is appropriate when victim and offender opt to enter an alternative process and that process is successfully undertaken. However, there are also situations where preclusion is not appropriate, and referral back to the criminal system may be both appropriate and necessary.

IV In what circumstances should an alternative trial process be referred back to the criminal justice system?

The Law Commission suggested three situations in which an alternative process could be referred back to the criminal justice system: ${ }^{38}$

(1) where information emerges that makes it unsuitable for the case to continue to be dealt with in an alternative process, such as information regarding additional offending;

(2) where the victim or the offender opts out of the alternative process;

(3) where no agreed outcome can be achieved, or the accused fails to participate in an acceptable way or to fulfil any undertakings made.

\footnotetext{
${ }^{37}$ Law Commission, "Submissions" above n 11, at 114.

${ }^{38}$ Law Commission, "Alternatives" above n 3, at 52.
} 
I now address some of the difficulties which may arise if referral back to the criminal justice system is permitted in each of these situations.

A Where information emerges that makes it unsuitable for the case to continue to be dealt with in an alternative process

The first situation the Law Commission envisages where referral back to the criminal system should be permitted is where information emerges during the alternative process that makes it unsuitable for the case to continue to be dealt with outside the criminal justice system. For example, the offender may admit to sexual offending against another person, or admit to a more serious level of offending against the original victim than was previously disclosed. In this situation, clear protocols are needed about who has the authority to discontinue the alternative process, how much say the victim has, and what level of additional offending is necessary to enable referral back to the criminal system.

It is first necessary to recognise that there is a fundamental tension between $\mathrm{RJ}$ and the criminal justice system. $\mathrm{RJ}$ is being proposed as an alternative response to sexual offending because it is inherently victim-centred. The criminal justice system is not solely victim-centred; it is also concerned with protecting public safety. Therefore, if an alternative process is to provide a complete alternative to criminal prosecution in some cases, it is necessary that the alternative process has a public safety element to it.

Under the proposed reform, a victim of sexual offending would make the decision to pursue a restorative process either at the point of laying a complaint with the police, or as an alternative to making a police complaint. That is, victims would either opt to be referred to an RJ provider when they talked to the police, or RJ providers could receive referrals directly from victims, who have not engaged at all with the criminal justice system. This is the current situation with Project Restore; referrals come from both the court and directly from the community. The offender would have to agree to participate in the RJ process.

At this point, the RJ provider would assess the case to determine whether or not it was appropriate for an alternative process. The Law Commission suggests that this decision should be made with regard to public safety; for example, the offender may have previous convictions which indicate that he or she poses a risk to public safety, and therefore the case should not be dealt with in an alternative process. The police and other 
agencies such as Child, Youth and Family would be available for consultation to assist the $\mathrm{RJ}$ provider in deciding whether RJ was an appropriate response to the particular case. If the RJ provider concludes that the case is inappropriate for an alternative process, it could be referred back to the criminal system. A difficult question arises, however, in a selfreferred case, where the victim does not want to pursue criminal prosecution. The victim may desire resolution through a restorative process, and has specifically chosen not to lay a complaint with the police, for whatever reason. But if the offending is serious, and the public may be at risk, should the RJ provider have the ability to inform the police?

As discussed earlier, one of the intentions of the alternative trial process is to give victims an alternative to criminal prosecution when the sentence the offender would receive is not consistent with the victim's wishes. For this reason, some have argued that if a victim chooses not to enter the criminal justice system initially, the choice as to whether or not to pursue criminal proceedings should always remain with him or her. ${ }^{39}$ If the victim opts for a restorative process and the offender does not agree, or the RJ provider looks at the case and decides it is not appropriate for RJ resolution, but the victim does not desire criminal prosecution, a purely victim-centred approach would say that the case should not be pursued. However, victim autonomy cannot be the only consideration if the alternative process is to be a complete alternative to criminal prosecution. Victim autonomy must be carefully balanced with public safety.

The Law Commission's recommendation that an alternative trial process be referred back to the criminal system in this situation is a clear signal that public safety should override victim autonomy in some cases. If information emerges which suggests that offending has occurred against other victims, or that the offending is of a more serious nature than initially thought, the RJ provider should have the ability to discontinue the restorative process in the interests of public safety, and the case should be referred back to the criminal justice system. In this situation, it should not matter whether or not the victim wants the offender to be formally charged. The State has the authority to decide whether criminal charges need to be laid.

Unfortunately, if there is a possibility that an offender may be criminally prosecuted even when the victim has chosen to self-refer to an RJ provider, this may deter some victims from referring themselves to RJ providers, particularly where they have self-

\footnotetext{
${ }^{39}$ Law Commission, "Submissions" above n 11, at 111.
} 
referred with the goal of avoiding involvement with the criminal justice system. However, it seems likely that for an alternative trial process to have any realistic chance of being implemented as a complete alternative to the criminal justice system there will need to be a "community safety override." 40 The difficulty is in determining at what threshold this override will need to be applied.

If information emerges regarding additional offending, and the RJ provider decides that this information renders the restorative process inappropriate, that is seen by the Law Commission as reaching the threshold where public safety must override victim autonomy. HELP $^{41}$ submitted that it is the RJ providers who must make the final decision, in collaboration with treatment agencies. ${ }^{42}$ Treatment agencies such as SAFE have protocols in place for this situation. ${ }^{43}$ This leaves RJ providers with a large amount of discretion, and one of the emerging themes from the public submissions is an emphasis on the importance of well-trained RJ facilitators who understand the psychology behind sexual offending, and can therefore recognise when an offender poses too great a risk to the public for the offending to continue to be dealt with in an alternative process. ${ }^{44}$

A different response is necessary in a situation where a victim self-refers to an RJ provider and the offender does not pose a risk to public safety. If the restorative process cannot go ahead, for whatever reason, the public safety override will not permit the provider to refer the case back to the criminal system, because there is no public safety concern. In this situation, it would be inappropriate for the RJ provider to refer the case to the police. The balancing act between victim autonomy and public safety is more heavily weighted towards the victim's wishes here. The victim has chosen not to make a police complaint. If the RJ provider can establish that the offender is not a public safety risk, it would be appropriate for the provider to speak to the victim about the possibility of laying a police complaint, but victim autonomy should preclude the provider from making a police complaint if the victim does not wish to do so.

\footnotetext{
${ }^{40}$ Law Commission, "Submissions" above n 11, at 109.

${ }^{41}$ HELP is a specialist provider of sexual abuse support services in Auckland. See $<$ http://helpauckland.org.nz/about-help $>$.

${ }^{42}$ Law Commission, "Submissions" above n 11, at 110.

${ }^{43}$ SAFE "Important Safe Policies" (2011) <www.safenz.org>.

${ }^{44}$ Law Commission, "Submissions" above n 11, at 107.
} 


\section{$B \quad$ Where the victim or the offender opts out of the alternative process}

The second scenario the Law Commission identified where referral back to the criminal justice system may be appropriate is where either the victim or the offender opts out after initiating a restorative process. RJ works on the basis that participation is voluntary. Therefore either party must have the opportunity to opt out of the process at any point. But if either party opts out, they risk their case being referred back to the criminal system. This can be seen to challenge the voluntary nature of RJ, because an element of coercion is present if an offender may face criminal prosecution when opting out of a restorative process. Some would argue that in order to preserve the voluntary nature of RJ, there should not be the threat of criminal proceedings if either party opts out of the restorative process. However, the offender must not be able to escape prosecution simply by agreeing to and subsequently withdrawing from a restorative process. Otherwise there is a risk that an offender will agree to a restorative process to avoid criminal proceedings, but choose to leave before any redress is agreed to or any outcomes are achieved.

Referral back to the criminal system is appropriate when the offender opts out of the process. But a different approach is necessary when the victim opts out. This scenario is similar to Situation A, because it questions whether the victim should have the authority to decide whether the case is referred back to the criminal system. The response should be the same as under Situation A. A public safety override should be applied if necessary. However, in a self-referred case where the offender poses no public safety risk, victim autonomy should be upheld. The victim should decide whether to refer the case back to the criminal system. As noted earlier, the public safety override takes the decision to pursue criminal prosecution out of the victim's control. This may have a chilling effect on victims' willingness to approach RJ providers. In this situation, clear information about what to expect from a restorative process would be particularly worthwhile, to minimise the number of victims who initiate a process but then opt out because it is not what they expect.

\section{Where no agreed outcome is achieved}

The tension between public safety and victim autonomy is again evident in the third situation proposed by the Law Commission where referral back to the criminal system would be possible: "where no agreed outcome can be achieved, or the accused fails 
to participate in an acceptable way or to fulfil any undertakings made. ${ }^{, 45}$ As discussed in Part II, the ability of RJ to provide flexible outcomes is one of the reasons it is proposed as an alternative to the criminal system. Indeed, the Law Commission suggests that restorative outcomes should be determined for each individual process: ${ }^{46}$

The process would involve the development of an outcome that was agreed between the victim and accused. Outcomes might include acknowledgement by the accused of the harm caused to the victim, apologies, participation in treatment, education or other [programmes] that addressed the behaviour and/or its causes, or agreement to pay reparation to the victim.

McDonald and Tinsley observe that "where participants take on responsibility and control for the outcome of a restorative process, the State clearly no longer has a monopoly over decision-making, but is potentially confined to providing information and resources." However, if a restorative process is to be a complete alternative to the criminal justice system, there is arguably a place for some level of State intervention in prescribing restorative outcomes, to ensure that the public sees offending being satisfactorily dealt with.

Public safety requires that offenders are not dealt with too leniently. Public satisfaction requires that offenders are not seen to be dealt with too leniently. RESTORE ensured that outcomes were not perceived to be too lenient by requiring that every responsible person undertook supervision for twelve months to ensure treatment was completed. ${ }^{48}$ Requiring every offender to receive treatment as a part of the restorative redress plan would be a helpful way of ensuring that the public feel comfortable about the outcomes of restorative processes. This would of course be resource intensive, but the Law Commission has suggested that the alternative process could be justified in cost-benefit terms because it is likely that levels of reoffending would be lowered. ${ }^{49}$

A further outcome which some in the sexual violence sector see as necessary, and therefore one that could be State-regulated, is that the offender "understands the fullness of

\footnotetext{
${ }^{45}$ Law Commission, "Alternatives" above n 3, at 52.

${ }^{46}$ At 52 .

${ }^{47}$ McDonald and Tinsley, above $\mathrm{n} 17$, at 429.

${ }^{48}$ Koss and others, above n 26, at 1451.

${ }^{49}$ Law Commission, "Alternatives" above n 3, at 52.
} 
the long-term consequences of their behaviour as part of a treatment programme." ${ }^{50}$ It has been suggested that if by the end of the process the offender still does not take responsibility for the harm caused, referral back to the criminal justice system could occur. The exception to this would be if the victim came to see the encounter in the same way as the offender, provided that the shared understanding is not a result of "continued grooming". ${ }^{51}$ It would be reasonable to require the offender to take responsibility for the harm he or she has caused as part of a prescribed requirement of attending a treatment programme.

State prescription of restorative outcomes risks inhibiting one of the greatest benefits of RJ: its flexibility. Braithwaite argues for caution about the extent to which restorative processes are regulated, to avoid impinging on the restorative nature of the process itself. ${ }^{52}$ However, given that this process would be a complete alternative to the criminal justice system, it is reasonable to expect that there will be some form of state regulation as to outcomes. Moreover, in this context, the flexibility of outcomes available in a restorative process addresses the issue of victims who do not desire incarceration of the offender; it is unlikely that any victim would argue against a requirement of treatment and acknowledgement of harm.

Shirley Jülich notes that New Zealand does not currently have legislation which can force an offender to complete agreed restorative conference outcomes. ${ }^{53}$ She argues that the implementation of a formal process for enforcing the fulfilment of conference outcomes is even more vital now that $\mathrm{RJ}$ providers are accepting referrals outside the court system. The same applies if restorative processes become an alternative to the criminal system; there will be no judge sentencing the offender and requiring the completion of restorative outcomes: a legislative enforcement mechanism will be needed. ${ }^{54}$ HELP has highlighted the importance of monitoring whether or not offenders are following through on their redress agreements, and suggested the need for consequences if agreements are not fulfilled. ${ }^{55}$ General submissions from the sexual violence sector on the Issues Paper

\footnotetext{
${ }^{50}$ Law Commission, "Submissions" above n 11, at 111.

${ }^{51}$ At 111 . The Project Restore model has protocols to recognise such "grooming."

52 John Braithwaite "Setting Standards for Restorative Justice" (2002) 42 Brit J Criminol 565.

${ }^{53}$ Shirley Jülich "Restorative Justice and Gendered Violence in New Zealand: A Glimmer of Hope" in James Ptacek (ed) Restorative Justice and Violence Against Women (Oxford University Press, Oxford, 2010) 247.

${ }^{54}$ At 247.

${ }^{55}$ Law Commission, "Submissions" above n 11, at 111.
} 
also recognised the need for "protocols for monitoring of following through on agreements and consequences for non-fulfilment of agreements." 56

Project Restore currently attempts to maintain contact with victim and offender until all conference outcomes are completed. Jülich observes however that unless a courtordered supervision incorporating the restorative conference outcomes is imposed at sentencing, fulfilling outcomes is left to "moral obligation and informal monitoring by family members and conference facilitators.

In the RESTORE programme, the CARB decided when a responsible person had not adhered to their agreement or to the programme rules. ${ }^{58}$ The decision rested with the CARB in recognition of the importance of maintaining the responsible person's relationship with the community. This could be worth investigating in New Zealand, especially given the apparent similarities between the CARB and the integration of maraebased justice into our criminal justice system. ${ }^{59}$

The Law Commission also notes in relation to this third scenario that "protocols would be needed for what constituted acceptable participation" ${ }^{~} 60$ in a restorative process. Helpful information should be gathered from the restorative process protocols of RESTORE and Project Restore. RESTORE had a reasonably strict policy as to referral back to the criminal justice system. In order for a case to proceed through the RESTORE programme, the programme would have to be recommended by the prosecutor. If the offender disobeyed any of the RESTORE rules, for example, by becoming abusive during a restorative conference, this would constitute sufficient grounds for return to the criminal justice system. ${ }^{61}$ If an offender fails to follow the participation protocols of the alternative process, this seems a straightforward situation in which it is appropriate to deal with the case through the criminal justice system rather than pursuing the alternative process. The benefits of RJ are only realised if both victim and offender participate fully. If the offender is not respecting the process, it will not yield successful outcomes for either party.

\footnotetext{
${ }^{56}$ Law Commission, "Submissions" above n 11, at 110.

${ }^{57}$ Jülich, above n 53, at 247.

${ }^{58}$ Koss and others, above n 26, at 1452.

${ }^{59}$ For example, the use of the Rangatahi Courts for youth offenders. See generally Matiu Dickson "The Rangatahi Court" (2011) 19 Wai L Rev 86.

${ }^{60}$ Law Commission, "Alternatives" above n 3, at 54.

${ }^{61}$ Koss and others, above n 26, at 1450.
} 
A more complicated situation, however, is one in which a victim believes that the offender has participated satisfactorily, but the RJ provider is concerned about the offender's participation or failure to complete outcomes. Equally complicated is the opposite scenario, where the victim is not satisfied with the offender's participation, but the $\mathrm{RJ}$ provider is satisfied. RJ aims to give victims greater autonomy, and it emphasises reconciliation between offender and victim. Thus there is a strong argument that the offender should be seen to have participated appropriately when the victim feels that this is so. But Meier emphasises that the decision as to whether the offender has participated satisfactorily (and whether or not they continue to be a risk to society) must be made by someone who is impartial and not involved in the conflict. ${ }^{62}$

Moreover, sexual offending is described as a "gendered harm", that is, a crime resulting from a power imbalance between (usually) men and women. There is a valid concern that "women will not receive a just result when the power dynamic that has lead to the harm is replicated in the restorative justice or conference process, ${ }^{, 63}$ and this concern may well influence how much authority is given to the victim to decide how satisfactory the alternative process has been. Arguably, if the RJ provider is concerned that an existing power imbalance may be continuing, they should be able to regard the process as unsatisfactory, even if the victim disagrees. Again, the tension between victim autonomy and public safety is relevant; where the RJ provider is concerned that a power imbalance is leading a victim to believe that an offender is participating satisfactorily, the RJ provider should have the ability to end the process and allow it to be referred back to the criminal justice system.

HELP noted that the loss of the right to use the criminal justice system could prove problematic if a victim remained unsatisfied even after the offender had fulfilled all undertakings made as a result of a restorative process. ${ }^{64}$ This is a valid concern, but it should not be considered a further situation in which referral back to the criminal justice system will be permitted. While it is true that RJ is a victim-centred response to offending, and victim satisfaction is important, it is unreasonable for a victim to have the right to require an offender to proceed through the criminal justice system if the offender has cooperated fully with the restorative process and fulfilled all the agreed undertakings.

\footnotetext{
${ }^{62}$ Bernd-Dieter Meier "Restorative Justice - A New Paradigm in Criminal Law” (1998) 6 Eur J Crime Cr L $\mathrm{Cr} \mathrm{J}$ at 135.

${ }^{63}$ McDonald and Tinsley, above $\mathrm{n} 17$, at 419.

${ }^{64}$ Law Commission, "Submissions" above n 11, at 111.
} 
Victims must therefore be well informed that criminal prosecution will be precluded if the restorative process is successful. The voluntary nature of the alternative process should ensure that the rights of the victims are upheld, provided that parties are well informed. At the end of the process, when the victim and offender are agreeing on redress outcomes, the victim should be reminded that, provided the offender fulfils all the undertakings he or she is making as part of the redress agreement, the criminal justice system will no longer be an available option. The victim may opt out of the alternative process at any point, but once they sign the redress agreement, they are essentially waiving their right to use the criminal justice system in the resolution of the case, provided that the offender fulfils the agreement.

Similarly, given that the inability to reach an agreement can be used as a legitimate reason to refer the case back to the criminal justice system, it would be useful to inform both parties about the type of redress outcomes previous agreements have included, so that both have a reasonable expectations. For example, it would be unreasonable to allow a particularly vindictive victim to proceed through the entire restorative process, but then refuse to conclude the process because he or she sought an excessive amount of compensation. While one of the benefits of RJ is the variety of available outcomes, RJ providers have the expertise to determine whether what the victim desires is reasonable. Offenders should not feel pressured to agree to unreasonable outcomes for fear of criminal prosecution.

Having considered some of the situations in which alternative trial processes should refer back to the criminal justice system, it is necessary to address one of the practical questions which arises when that referral occurs.

$V$ If an alternative process is referred back to the criminal system, what should happen to material disclosed?

If a situation arises during an alternative process which results in referral back to the criminal justice system, protocols are needed as to what to do with information that has been revealed during the process. The Law Commission recommended that in an alternative trial process ${ }^{65}$

\footnotetext{
${ }^{65}$ Law Commission, "Alternatives" above n 3, at 50.
} 
proceedings would be privileged, i.e. nothing the accused said in the course of the process could be used as evidence in any later criminal proceedings. However, information provided by the accused could be used to trigger further investigation by police, the outcome of which could be used if prosecution for that offence or any other offence ensued.

The Criminal Bar Association submission questioned "whether the content of matters disclosed in the proceedings would be privileged entirely, or only content relating to the proceedings at issue. ${ }^{, 66}$ Overall, the proposition that proceedings be privileged was supported by the public submissions, although with the ability for information to be provided to police "to trigger further investigation." ${ }^{, 67}$ This issue is particularly relevant if the alternative process is referred back to the criminal system because information regarding additional offending emerges.

There is a narrow distinction between prohibiting material from restorative proceedings being used as evidence, but allowing it to be given to police in order to trigger further investigation. This issue of privileged proceedings emphasises a second underlying tension between RJ and the criminal justice system: balancing due process and the procedural rights of offenders with public safety. ${ }^{68}$ Meier acknowledges that procedural rights are "the weak spot of restorative justice." 69 He suggests that we must "undertake a complicated balancing act between the claim to informality and autonomy on the one hand and the need to observe the procedural rights and safeguards of the persons involved on the other."70

In the current RJ context in New Zealand, there is a general acceptance that the proceedings of restorative conferences remain confidential. However, only limited confidentiality is currently offered in restorative processes for sexual offending. ${ }^{71}$ One of the reasons for this is the risk to public safety if further offending is revealed in the restorative process. Jülich's research of child sexual abuse survivors found that they were concerned about confidentiality "in relation to disclosures arising within restorative

\footnotetext{
${ }^{66}$ Law Commission, "Submissions" above n 11, at 108.

${ }^{67}$ At 110 .

${ }^{68}$ McDonald and Tinsley, above $\mathrm{n} 17$, at 426.

${ }^{69}$ Meier, above n 62, at 132 .

${ }^{70}$ At 133.

${ }^{71}$ McDonald and Tinsley, above n 17, at 426.
} 
conferences that indicated other serious offending had occurred or was occurring., 72 Current practice is that if other offences are admitted, or if any deadly threats are made, this is reported to the police. ${ }^{73}$ Of course, this position may need to change if restorative conferences are to be used as a complete alternative to the criminal justice system.

There are strong arguments for keeping restorative proceedings confidential and inadmissible as evidence in criminal proceedings. Overall, RJ literature appears to be in favour of confidentiality, with a view to upholding offenders' rights as much as possible. Those who conduct restorative processes see confidentiality as being essential to the success of the restorative process itself. HELP submitted that ensuring privileged proceedings creates "a safer environment for offenders to potentially take fuller responsibility for the harm they have caused." ${ }^{, 74}$ Similarly, Bowen and colleagues argue that confidentiality is "a key element in establishing a safe environment in which open communication could occur between all participants." 75 Participants who are assured of confidential proceedings can speak openly, facilitating honest discussion. There is a legitimate concern that offenders may not contribute fully to the process if they know that what they disclose may later be used as evidence in a criminal proceeding.

Bowen and colleagues go so far as to recommend that there should be legislation in New Zealand that assures absolute confidentiality for restorative proceedings, prohibiting further prosecution on the basis of anything an offender admitted during a restorative conference. ${ }^{76}$ Tina Ikpa advocates for a similar legislative response. ${ }^{77}$ As yet, no such legislation has been enacted, and New Zealand courts have not yet been required to address the subject.

Restorative conference reporting may also need to change if restorative processes are to be used as a complete alternative to the criminal justice system. Currently conference reports are used to inform the courts of the discussions that took place. Thus judges can have insight into the restorative process. Any acceptance of responsibility or

\footnotetext{
${ }_{73}^{72}$ Jülich, above n 53, at 249.

${ }^{73}$ At 249.

${ }^{74}$ Law Commission, "Submissions" above n 11, at 111.

75 Jülich, above n 53, at 249.

${ }^{76}$ Helen Bowen, Jim Boyack and Stephen Hooper The New Zealand Restorative Justice Practice Manual (Auckland, Restorative Justice Trust, 2000).

${ }^{77}$ Ikpa, above n 10, at 301.
} 
demonstration of remorse can be taken into account when sentencing. ${ }^{78}$ Given the open nature of New Zealand's judicial system, the conference reports are essentially public documents. The reports themselves typically include word-for-word accounts of some aspects of the conference. ${ }^{79}$

Project Restore have found that their reports sometimes contain information that the prosecution or defence can use unfairly against either party. One way they have attempted to address this problem is to provide a report that outlines the main themes discussed in the conference, as opposed to a chronological verbatim account. The New Zealand courts did not comment on this change in reporting style. However, one offender who read the more thematic report of his restorative conference did not feel that it was an accurate account of what had taken place. This demonstrates the complexity of thematically summarising restorative conferences. ${ }^{80}$

Jülich notes that RESTORE in Arizona does not provide any report of the conference apart from the agreed outcomes. The content of RESTORE conferences is confidential and no written record of the conference is made "so that nothing that is disclosed can be used in subsequent legal actions should the restorative process fail." While following RESTORE's approach would uphold the desire for confidentiality, it is also much less transparent, and Jülich recognises that there is a certain level of public interest in having insight into a process which is conducted in private. ${ }^{82}$ If restorative processes were to be used as a complete alternative to the criminal justice system, conference reports would no longer be necessary to assist judges in sentencing. However, Jülich's argument about public interest in a private process is particularly relevant if the restorative process is a complete alternative to criminal prosecution.

It is important that criminal justice is a public process. This conflicts directly with the interest in restorative conferences remaining confidential. RESTORE balanced these conflicting interests by allowing observers to attend conferences if there was prior notification and the victim, offender and their supporters agreed. Those who requested attendance included prosecutors, police officers, correctional officers, defence lawyers, and

\footnotetext{
${ }^{78}$ Sentencing Act 2002, s 8(j).

${ }^{79}$ Jülich, above n 53, at 250 .

${ }^{80}$ At 250.

${ }^{81}$ Koss and others, above n 26, at 1449.

${ }^{82}$ Jülich, above n 53, at 250 .
} 
additional friends and family. However, all participants were required to sign a confidentiality agreement. This system allowed RESTORE to balance the recognition of justice as a public process, but also to leave the victim in control of the process, by enabling them to deny the presence of additional observers, and protecting the offender by requiring observers to keep the proceedings confidential. ${ }^{83}$

As previously discussed, there is a need for a "public safety override" to be available if offenders do reveal information regarding other offending during restorative proceedings. This is because using restorative processes as a complete alternative to the criminal justice system means that the restorative process will need to fulfil, at least to some extent, the role the criminal justice system plays in protecting public safety. It is unfortunate that this may inhibit the openness and honesty that is required for a successful restorative conference to take place. However the offender will retain some protection in that the information will not be admissible as evidence, it will only be available to the police to trigger further investigation.

While clear protocols around the confidentiality of restorative proceedings will be required, there is also an issue as to the very fact of an offender's agreement to participate in an alternative process, and whether this information should also be kept confidential.

For an offender to participate in a restorative process, he or she must at least acknowledge that a sexual encounter took place. Project Restore requires an even higher standard of acknowledgement and responsibility. Their experience shows that if the offender does not acknowledge his or her actions having caused harm, the restorative conference can be highly confrontational, which is not conducive to any restorative outcome. This requirement of acknowledgement of harm or sexual encounter is not currently problematic, because RJ processes are being used in conjunction with criminal prosecution, and occur at various points throughout the criminal process, only after a guilty plea has been entered. The situation will be very different if the restorative process is a complete alternative to criminal prosecution, which could result in criminal prosecution if the restorative process failed.

\footnotetext{
${ }^{83}$ Mary P Koss "Restorative Justice for Acquaintance Rape and Misdemeanor Sex Crimes" in James Ptacek (ed) Restorative Justice and Violence Against Women (Oxford University Press, Oxford, 2010) 218 at 223.
} 
Whether the standard for acknowledgement is simply recognition of a sexual encounter or the higher standard of recognition of harm caused, this may be more than the offender would be willing to admit to in criminal proceedings. It is one thing for an offender to admit to an act in order to make amends with the victim and offer reparation in the form of monetary compensation or a commitment to attending a treatment programme. It is quite another thing to admit to an event occurring which may result in a substantial prison sentence, especially when there is a strong possibility that guilt would not otherwise be proved beyond reasonable doubt in a criminal court.

In New Zealand's current RJ context, the Law Commission states that as long as an offender's participation in a restorative process is voluntary, the offender waives their privilege against self-incrimination. ${ }^{84}$ However, the use of RJ as an alternative process rather than during the criminal justice process after a guilty plea has been entered, may threaten offenders' rights more significantly. An offender's privilege against selfincrimination is far more likely to be overridden if he or she can opt for an alternative restorative process, having admitted a sexual encounter of some sort, but then be referred back to the criminal system for any of the reasons discussed in Part IV above.

For this reason, if a restorative process is referred back to the criminal justice system, the fact that the offender agreed to participate in the process should be privileged, and the privilege should belong to the offender. Otherwise it will be apparent to the jury that the offender has at least acknowledged that a sexual encounter of some description took place, and at most has admitted guilt by agreeing to participate in a restorative process. Currently, participation in a restorative process can be a mitigating factor at sentencing. ${ }^{85}$ If the privilege belongs to the offender, and they choose to enter a guilty plea when their case is referred back to the criminal justice system, they could choose to disclose their beginning a restorative process, as demonstrating remorse and a desire to make amends with the victim. There is the potential for this to be abused, in that an offender could begin a restorative process and then quickly opt out, with the goal of reducing their sentence. However, this potential exists with the current availability of RJ, and it does not seem to have been a problem, given that participation in RJ remains a mitigating factor at sentencing.

\footnotetext{
${ }^{84}$ Law Commission The Privilege Against Self-Incrimination (NZLCPP25, 1996) 40.

${ }^{85}$ Sentencing Act 2002, s 8(j).
} 


\section{Conclusions}

New Zealand has always taken an innovative approach toward restorative justice. The Law Commission's proposal of an alternative restorative process for some sexual offence cases responds to the call for a wider range of possible responses to sexual offending. However, the availability of a restorative process as a complete alternative to the criminal justice system requires careful consideration of the balance between victim autonomy on the one hand, and public safety on the other.

$\mathrm{RJ}$ can be an appropriate response to some cases of sexual offending because it gives victims greater autonomy and greater flexibility of outcomes. It may also provide resolution for cases which would not otherwise be satisfactorily addressed through the traditional criminal system. There remain legitimate concerns about the suitability of RJ for addressing a gendered harm such as sexual offending. However, the experiences of RESTORE and Project Restore suggest that well-trained and well-resourced RJ providers have the ability to address many of these concerns.

If victim and offender opt to pursue a restorative process as an alternative to criminal prosecution, it is appropriate that criminal prosecution is subsequently precluded, provided that the offender participates in good faith and fulfils all undertakings. But the public safety role that the alternative process must play demands that referral back to the criminal system is possible where the offender poses a public safety risk. If information regarding additional offending comes to light, or either party opts out of the process, or the offender does not participate satisfactorily, RJ providers must be able to apply a public safety override, allowing them to refer the case to the criminal system regardless of the wishes of either party. While greater victim autonomy is an important benefit of using restorative processes, it cannot be prioritised over public safety.

There is room for the State to play a role in regulating restorative outcomes, to ensure that any alternative process is seen to be dealing with sexual offences satisfactorily. Requirements such as attending treatment programmes and taking responsibility for harm caused would be appropriate outcomes to be State-regulated.

If an alternative process is referred back to the criminal system, any information revealed in restorative proceedings should be privileged, and that the privilege should 
belong to the offender. While information can be provided to the police to assist them in investigating additional offending, the information should not be admissible as evidence in criminal proceedings. Confidentiality is vital for ensuring open and honest participation in restorative processes. Moreover, the offender's agreement to participate in an alternative process should also be privileged, so that the offender's acknowledgement of a sexual encounter taking place is not available to a jury in a subsequent criminal prosecution.

The questions which arise at the interface between RJ and the criminal justice system are complex. But they should not discourage New Zealand's implementation of a restorative process as a complete alternative to the criminal justice system in some cases of sexual offending. 


\section{Bibliography}

\section{A Legislation \\ $1 \quad$ New Zealand}

Crimes Act 1961.

Parole Act 2002.

Sentencing Act 2002.

\section{B Books and Chapters in Books}

Kathleen Daly "Revisiting the Relationship between Retributive and Restorative Justice" in Heather Strang and John Braithwaite (eds) Restorative Justice: Philosophy to Practice (Ashgate, Aldershot, 2000).

Shirley Jülich "Restorative Justice and Gendered Violence in New Zealand: A Glimmer of Hope" in James Ptacek (ed) Restorative Justice and Violence Against Women (Oxford University Press, Oxford, 2010).

Mary P Koss "Restorative Justice for Acquaintance Rape and Misdemeanour Sex Crimes" in James Ptacek (ed) Restorative Justice and Violence Against Women (Oxford University Press, Oxford, 2010).

Mary P Koss, Karen J Bachar and C Quince Hopkins "An Innovative Application of Restorative Justice to the Adjudication of Selected Sexual Offences" in H Kury and J Obergfell-Fuchs (eds) Crime Prevention - New Approaches (Wesier Ring, Mainz, Germany, 2003).

Elisabeth McDonald and Yvette Tinsley "Rejecting 'One Size Fits All': Recommending a Range of Responses" in Elisabeth McDonald and Yvette Tinsley (eds) From "Real Rape" to Real Justice (Victoria University Press, Wellington, 2011). 
Howard Zehr The Little Book of Restorative Justice (Good Books, Intercourse (Penn), 2003).

\section{Journal Articles}

Bruce Archibald “Coordinating Canada's Restorative and Inclusionary Models of Criminal Justice: The Legal Profession and the Exercise of Discretion Under a Reflexive Rule of Law" (2005) 9 Can Crim L Rev 215.

John Braithwaite "Setting Standards for Restorative Justice" (2002) 42 Brit J Criminol 563.

Kathleen Daly "Restorative justice: The real story" (2002) 4 Punishment and Society 55.

Kathleen Daly, "Restorative Justice and Sexual Assault: An Archival Study of Court and Conference Cases" (2006) 46 Brit J Criminol 334.

Kathleen Daly "Setting the Record Straight and a Call for Radical Change: A Reply to Anne Cossins on 'Restorative Justice and Child Sex Offences"” (2008) 48 Brit J Criminol 557.

Arielle Dyland, Cheryl Regehr and Ramona Alaggia "And Justice for All? Aboriginal Victims of Sexual Violence" (2008) 14 Violence Against Women 678.

Tina S Ikpa "Balancing Restorative Justice Principles and Due Process Rights in Order to Reform the Criminal Justice System” (2007) 24 Wash. U.J.L \& Pol’y 301.

Shirley Jülich and John Buttle "Beyond Conflict Resolution: Towards a Restorative Practice Process for Sexual Violence” (2011) 8 Te Awatea 21.

Mary P Koss, Karen J Bachar, C Quince Hopkins and Carolyn Carlson "Expanding a Community's Justice Response to Sex Crimes Through Advocacy, Prosecutorial, and Public Health Collaboration: Introducing the RESTORE Program" (2004) 19 J Interpers Violence 1435.

Anne-Marie McAlinden "The use of shame with sexual offenders" (2005) 45 Brit J Criminol 373. 
G Mousourakis "Restorative Justice: Some Reflections on Contemporary Theory and Practice" (2004) 29 Journal for Juridical Science 1.

Bernd-Dieter Meier "Restorative Justice - A New Paradigm in Criminal Law" (1998) 6 Eur J Crime Cr L Cr J 125.

Mary Ellen Reimund "The Law and Restorative Justice: Friend or Foe? A Systemic Look at the Legal Issues in Restorative Justice" (2005) 53 Drake L Rev 667.

\section{Parliamentary and Government Materials}

Law Commission Alternative Pre-Trial and Trial Processes: Possible Reforms (NZLCIP30, 2012).

Law Commission Alternative Pre-Trial and Trial Processes: Summary of Submissions to Consultation (2012).

Law Commission The Privilege Against Self-Incrimination (NZLCPP25, 1996).

Pat Mayhew and James Reilly The New Zealand Crime and Safety Survey 2006: Key Findings (Ministry of Justice, Wellington, 2007).

Ministry of Justice Principles of Best Practice for Restorative Justice Processes in Criminal Cases (2003) < www.justice.govt.nz/publications/global-

publications/r/restorative-justice-in-new-zealand-best-practice>.

\section{E Reports}

Shirley Jülich, John Buttle, Christine Cummins and Erin V Freeborn Project Restore: An Exploratory Study of Restorative Justice and Sexual Violence (AUT, Auckland, 2010).

Sue Triggs, Elaine Mossman, Jan Jordan and Venezia Kingi Responding to Sexual Violence: Attrition in the New Zealand Criminal Justice System (Ministry of Women's Affairs, Wellington, 2009). 


\section{F Dissertations}

Shirley Jülich "Breaking the Silence: Restorative Justice and Child Sexual Abuse" (PhD Thesis, Massey University, 2001).

\section{G Internet resources}

HELP Support for Sexual Abuse Survivors “About HELP” <http://helpauckland.org.nz>.

SAFE “Important Safe Policies” (2011)<www.safenz.org>.

\section{H Other resources}

Helen Bowen, Jim Boyack and Stephen Hooper The New Zealand Restorative Justice Practice Manual (Restorative Justice Trust, Auc

\section{Word Count}

The text of this paper (excluding abstract, footnotes and bibliography) comprises approximately 8200 words. 